\title{
VISÃO BASEADA EM RECURSOS NO CLUSTER VITIVINÍCOLA DA SERRA GAÚCHA
}

\author{
Resource-based vision in the cluster of Saw Gaúcha Wildlife
}

Bibiana Skrebsky de Almeida ${ }^{1}$
Flavia Camargo Bernardi $^{2}$
Uiliam Hahn Biegelmeyer $^{3}$
Tânia Craco $^{4}$
Maria Emilia Camargo ${ }^{5}$
Alice Munz Fernandes ${ }^{6}$
Mayara Pires Zanotto ${ }^{7}$
Recebido em: 26 jul. 2018
Aceito em: 16 out. 2018

Resumo: O presente estudo foi realizado por meio de uma revisão da literatura sobre clusters e a Visão Baseada em Recursos (RBV). O artigo teve como objeto de estudo o cluster vitivinícola da Serra Gaúcha/RS. Com o referido estudo foi possível compreender como a RBV pode ser utilizada para criar vantagens competitivas. A metodologia utilizada foi uma pesquisa básica de revisão de literatura, exploratória, bibliográfica e documental. Averigou-se como resultado que o cluster apresenta potencial para se destacar internacionalmente, desde que analise seus recursos e a maneira como eles podem ser estratégicos, principalmente com espumantes e vinhos tintos da variedade merlot, que já possuem reputação firmada. Também foi observado que o cluster apresenta alguns desafios: distribuição, equilibrio entre a produção e a oferta e a concorrência com vinhos importados.

Palavras-Chave: Clusters. Visão Baseada em Recursos. Vantagem Competitiva.

Abstract: The present study was carried out through a review of the cluster literature and the Resource Based View (RBV). The article had as object of study the viticulture cluster of Serra Gaúcha / RS. With this study it was possible to understand how RBV can be used to create competitive advantages. The methodology that was used, was based in a basic research of literature review, exploratory, bibliographical and documentary. It has emerged that the cluster has the potential to stand out internationally as long as it

\footnotetext{
${ }^{1}$ Bacharel em Comunicação Social com Habilitação em Publicidade e Propaganda pela Escola Superior de Propaganda e Marketing - Porto Alegre. E-mail: bibiana.skrebsky@gmail.com.

${ }^{2}$ Mestre em Administração de Empresas pela Universidade de Caxias do Sul. E-mail: flaviacamargo@gmail.com.

${ }^{3}$ Doutor em Administração da Universidade de Caxias do Sul e da Pontificia Universidade Católica do Rio Grande do Sul - Associação. Mestre em Administração UCS,Docente dos cursos de especialização e MBA da Universidade de Caxias do Sul e FSG. E-mail: uiliam.hb@terra.com.br.

${ }^{4}$ Doutora em Administração da Universidade de Caxias do Sul e da Pontificia Universidade Católica do Rio Grande do Sul - Associação. Docente do Instituto federal do Rio Grande do Sul. E-mail: tania.craco@farroupilha.ifrs.edu.br. ${ }^{5}$ Pós Doutora em Controle Estatítico do Processo pela Universidade de Kazan Russia, Professora da Universidade de Caxias do Sul. E-mail: mariaemiliappga@gmail.com.

${ }^{6}$ Doutoranda em Agronegócios pela UFRGS, Mestre em Administração pela UCS. E-mail: alicemunz@gmail.com.

${ }^{7}$ Doutoranda em Administração pela UCS, Mestre em Administração. E-mail: mpzanotto@gmail.com.
} 
analyzes its resources and the way they can be strategic, especially with sparkling wines and merlot red wines, which already have a reputation. It was also observed that the cluster presents some challenges: distribution, balance between production and supply and competition with imported wines.

Keywords: Clusters. Resource Based View. Competitive Advantages.

\section{INTRODUÇÃO}

As oportunidades e ameaças presentes no mundo dos negócios vêm crescendo na medida em que as empresas evoluem e tornam-se competitivas. A competitividade, porém, é algo que deve ser trabalhado num processo contínuo, de forma que crie vantagens competitivas sustentáveis.

Nesse contexto, uma das fontes de vantagens competitivas são as aglomerações geográficas, que possibilitam a formação de cadeias de suprimentos, facilidade de comunicação, poder de barganha com fornecedores, entre outras vantagens oferecidas pela proximidade geográfica (SCHMITZ, 1999).

No Brasil, um dos setores principais organizados em aglomerados geográficos é o setor vitivinícola, no qual as empresas aproveitam a existência de um território que reúne fatores climáticos, características do solo e das videiras, a cultura local, e todos esses fatores impactam na qualidade do vinho, bem como nas vantagens competitivas das vinícolas, produtores de uva, etc (FENSTERSEIFER e WILK, 2005). Assim a denominação mais utilizada para esses algomerados chama-se Clusters. Clusters não são únicos, ao contrário, são altamente típicos. Nessa conjuntura, encontra-se um paradoxo: as vantagens competitivas duradouras de uma economia global cada vez mais se encontram nas coisas locais - conhecimento, relacionamento e motivação que os concorrentes distantes não podem imitar (PORTER, 1998).

Há também presentes no cluster os recursos coletivos que possuem natureza estratégica e são dificilmente imitáveis, transformando-se em potenciais vantagens competitivas perante outros clusters ou regiões concorrentes (FENSTERSEIFER; WILK, 2005).

Nesse sentido, a Visão Baseada em Recursos (RBV) torna-se muito importante para que o setor vitivinícola ganhe vantagens competitivas, ainda mais quando vemos que produtos internacionais chegam ao Brasil com preços competitivos e qualidade similar ou maior que os vinhos produzidos nacionalmente.

O cluster vitivinícola da Serra Gaúcha, localizado na região nordeste do estado do Rio Grande do Sul, concentra cerca de $80 \%$ da produção de vinhos do país e uma área de vinhedos com mais de 34.000 ha. A aglomeração engloba cerca de 600 vinícolas e mais de 13.000 produtores de vinhos, quase, em sua totalidade, descendentes de imigrantes italianos (FENSTERSEIFER, 2007; IBRAVIN, 2014).

Com o presente artigo pretende-se realizar um levantamento bibliográfico e 
documental sobre os temas relevantes, realizar uma análise dos conceitos e das formas de aplicação da VBR no cluster para responder a seguinte pergunta: de que forma a VBR pode ser utilizada para trazer vantagens competitivas sustentáveis para o Cluster Vitivinícola da Serra Gaúcha?

\section{CLUSTERS}

Para Porter (1998) clusters são concentrações de empresas e instituições interconectadas em um determinado setor. Ou seja, os clusters são aglomerados com interesses e habilidades comuns. Complementa Becattini (1990) que clusters são entidades sócio-econômicas caracterizadas pela presença de uma população de empresas bem como uma população de consumidores em uma localização naturalmente e historicamente limitada. Existem também outras denominações para essas aglomerações, dentre as quais se destaca "Sistemas Produtivos Locais" (SPLS) e "Arranjos Produtivos Locais" (APLS), que pressupõem a existência de aprendizagem e governança para o desenvolvimento de inovações (CASSIOLATO e LASTRES, 2003).

Atualmente existe muito interesse em fazer parte de um cluster, tendo em vista que as atividades econômicas em determinados locais tendem a gerar vantagens como: eficiência com baixo custo, flexibilidade devido à elevada mobilidade de recursos humanos e desenvolvimento de outros recursos, e a inovação (SÖLVELL, 2009).

Além disso, os aglomerados têm mais possibilidades de obter ganhos coletivos em seus processos produtivos (MARSHALL, 1890; PORTER, 1998; SCHMITZ, 1999; CASSIOLATO e LASTRES, 2003). Desse modo, o fator regional se torna uma das fontes de vantagens competitivas para as empresas do aglomerado, podendo levá-las a um desempenho superior em suas atividades.

Nesse sentido, as vantagens de um cluster surgem quando seus personagens tornamse responsáveis por ações conjuntas e investimentos visando a geração de ganhos coletivos. Esses personagens devem ser capazes de identificar necessidades, coordenar empreendimentos cooperativos e buscar soluções para os possíveis problemas decorrentes dessas ações. Essas vicissitudes como os oportunismos e os "caronas", que se aproveitam das vantagens do cluster gerando um efeito negativo, já que não investem em ações coletivas, mas acabam se beneficiando dos ganhos coletivos decorrentes da inserção na aglomeração (FENSTERSEIFER e WILK, 2005; NADVI e SCHMITZ, 1999). Outro aspecto importante é que a concorrência das empresas que atuam no setor não se limita ao nível organizacional, mas abrange os recursos associados ao país e ao cluster, como por exemplo, a reputação de um produto originado em uma determinada região (FENSTERSEIFER e WILK, 2005; MARSHALL, 1890; PORTER, 1998; SCHMITZ, 1999; CASSIOLATO e LASTRES, 2003). 
Fazer parte de um cluster, portanto, permite às empresas a operarem mais produtivamente em fornecimento de insumos, acesso à informação, tecnologias, instituições, coordenar ações com empresas relacionadas, além de medir e motivar melhorias (PORTER, 1998). Nesse contexto, o fator regional pode ser considerado uma grande fonte de vantagem competitiva, motivando-as para um desempenho superior.

As relações consonantes ao cluster possibilitam a geração de recursos compartilhados pelas empresas localizadas na mesma aglomeração geográfica (MOLINA-MORALES, 2001; WILK e FENSTERSEIFER, 2003). De acordo com Becattini (1991), um aglomerado geográfico ou cluster é um agente coletivo que depende de uma forte rede de relacionamentos com o mercado final ao mesmo tempo em que cria uma imagem do cluster, independente da imagem particular das empresas que o formam.

Dentro de um cluster as empresas também podem se organizar e investir em modelos de treinamento e desenvolvimento, o que resulta em um ganho direto nas pessoas envolvidas e consequentemente gera uma vantagem competitiva conjunta( MAFEZOLLI,2017).

A identidade do cluster pode influenciar diretamente no seu desempenho e, dessa forma, na competitividade das empresas de diversas formas. Nessa visão, na perspectiva de RBV, a dinâmica das relações interorganizacionais existentes no cluster poderá gerar recursos compartilhados, que não podem ser imitados pelos concorrentes ou por empresas externas ao cluster, além de proporcionar oportunidades de mercado que não são acessíveis às empresas fora do aglomerado (MASKELL, 2001; MOLINA- MORALES, 2001; WILK e FENSTERSEIFER, 2003; MENDEZ e MERCIER, 2006; WILK, 2006; BELSO- MARTINEZ, 2006).

Um cluster pode ser compreendido como um conjunto de recursos, cuja produtividade dependerá das percepções dos gestores. Ao analisar um cluster deve- se prestar atenção naqueles recursos que são propriedade singular da empresa e perceber a possibilidade de identificar outros, que possuem acesso restrito e que não pertencem a uma empresa individual, mas que podem ser acessados por firmas que seguem algumas estratégias determinadas, ou que estão mais preparadas para acessá-los (FENSTERSEIFER e WILK, 2005; PORTER, 1998). Para dar base a análise do cluster, bem como ao planejamento estratégico, é importante conhecer a Visão Baseada em Recursos (RBV), cujos conceitos são apresentados no item a seguir.

\section{VISÃO BASEADA EM RECURSOS}

A RBV foi desenvolvida inicialmente para dar base à obtenção de vantagens competitivas sustentáveis no mercado, através dos recursos estratégicos das empresas (WERNERFELT, 1984; BARNEY, 1986, 1991; DIERICKX e COOL, 1989; GRANT, 1991; PETERAF, 1993). De acordo com Molina-Morales (2001), as empresas em um determinado cluster 
possuem acesso a recursos compartilhados que possibilitam um desempenho superior ao das empresas que não fazem parte dos aglomerados. Esses recursos compartilhados são gerados nas peculiaridades e particularidades das relações entre empresas presentes no cluster (DYER e SINGH, 1998).

Wernerfelt (1984) define recursos de forma ampla, os quais podem ser definidos como ativos tangíveis e intangíveis vinculados à empresa, tais como: marca, conhecimento tecnológico, capital humano, maquinário, entre outros. Porém, outros termos existem na caracterização dos recursos, como: recursos estratégicos da empresa (BARNEY, 1991), ativos invisíveis (ITAMI, 1987), ativos estratégicos específicos da firma (DIERICKX e COOL, 1989), competência essencial (PRAHALAD e HAMEL, 1990), capacidades dinâmicas (TEECE, PISANO e SHUEN, 1997).

As competências podem ser definidas como rotinas de busca que atuam nos recursos da empresa, podendo atuar em duas maneiras: refinamento ou acumulação incremental de um recurso; ou renovação, por meio de descobertas de novas e mais eficientes funções produtivas (NANDA, 1996). Porém, é necessário atentar para a necessidade das empresas em desenvolverem competências essenciais no desenvolvimento de produtos inovadores, a custos menores e mais rápido que a concorrência, principalmente quando se fala em competitividade a longo prazo. No curto prazo, a competitividade de uma empresa deriva de seus atributos de preço ou desempenho em produtos existentes, o que pode ser facilmente imitado pela concorrência, sendo então não sustentável (PRAHALAD e HAMEL, 1990).

$\mathrm{Na}$ visão estratégica de recursos, a empresa possui vantagem competitiva quando implementa estratégias de criação de valor para o cliente, que não pode ser implementada simultaneamente por concorrentes. Já a vantagem competitiva sustentável ocorre quando as empresas concorrentes não tem capacidade de duplicar os benefícios gerados pela implementação de uma determinada estratégia. Mas é preciso entender que ser sustentável não significa que a estratégia durará pra sempre, mas sim que não será superada pela concorrência por um determinado período de tempo (BARNEY, 1991).

Barney (1991) aponta que os mecanismos que possibilitam uma imitação imperfeita, ou seja, a dificuldade da concorrência em imitar uma estratégia, são os seguintes: a dependência da trajetória da empresa, que é única; a ambiguidade causal; e a complexidade social. A dependência da trajetória diz respeito aos recursos que foram desenvolvidos no decorrer da história da empresa, não podendo ser imitados pela concorrência, levando em consideração que os erros, acertos e aprendizagens são únicos de cada organização. A ambiguidade causal indica a impossibilidade da identificação dos recursos que geram vantagem competitiva sustentável, impedindo a imitação pela concorrência. Por fim, os recursos podem ser gerados a partir da complexidade de fenômenos sociais, que estão além da capacidade de gestão da empresa. 
É importante destacar também que os recursos da empresa não se limitam aos gerados internamente, ou seja, a empresa também poderá acessar recursos decorrentes de atores externos, como fornecedores, compradores, membros do cluster ou mesmo os concorrentes (DYER e SINGH, 1998; DAS e TENG, 2000; LAVIE, 2006). Nesse contexto, Mesquita, Anand e Brush (2008) apontam que, enquanto a RBV explica que a competitividade vem dos recursos valiosos e nas capacidades de difícil imitação no nível da organização, a Visão Relacional explica que a competitividade não surge somente da firma, mas também das relações interorganizacionais, muito importantes quando se fala em aglomerados ou clusters.

As alianças interorganizacionais podem ser concebidas como estratégias combinadas e acesso a recursos, permitindo a redução de tempo e investimento para a formação dos recursos necessários para a formação e sustentação de uma vantagem competitiva (WILK e FENSTERSEIFER, 2005). Nesse sentido, pode-se inferir que a RBV e a Visão Relacional são complementares, principalmente quando trata-se de um cluster. Lavie (2006) utiliza a Visão Relacional para analisar a aplicabilidade da RBV no ambiente das redes ou aglomerados. Os recursos de um aglomerado são externos, incorporado nas empresas da aliança resultando em oportunidades estratégicas e geração de valor (GULATI, 1999).

Dessa forma, a capacidade de empresas, conectadas ou aglomeradas em um cluster, de obterem vantagem competitiva sustentável depende tanto da RBV quanto das suas capacidades relacionais, ou seja, das suas capacidades de formar e manter relacionamentos interativos valiosos com os membros da aliança (LAVIE, 2006).

Fensterseifer e Wilk (2005) apontam a existência de três categorias de recursos em clusters - recursos sistêmicos, de acesso restrito e singular. Os recursos singulares pertencem às empresas individuais e possibilitam desempenhos heterogêneos entre as empresas do cluster, conforme os pressupostos da Visão Baseada em Recursos (RBV), que será discutida mais adiante neste estudo. Já os recursos singulares pertencem às empresas individuais e tem seu suporte estratégico dependente da trajetória, de assimetrias de conhecimentos, ambiguidade causal ou ainda pela complexidade social dos recursos. Também de acordo com a RBV, os recursos singulares promovem desempenhos heterogêneos entre as empresas inseridas no mesmo cluster.

Os recursos sistêmicos, por sua vez, são aqueles que não pertencem a empresas individuais, porém impactam diretamente o desempenho de todas as empresas pertencentes ao cluster. Esses recursos decorrem das relações dinâmicas do cluster onde não há concorrência entre as empresas, pois podem ser usufruídos da mesma maneira por todas elas. Nesses recursos, há uma dependência da trajetória do cluster (FENSTERSEIFER e WILK, 2005).

Por fim, os recursos de acesso restrito não são pertencentes exclusivamente a nenhuma empresa, podendo ser acessados somente por um grupo distinto de firmas do cluster. Esses recursos beneficiam somente aquelas empresas que adotam uma determinada 
conduta no ambiente em que estão inseridas. O acesso a eles ocorre por diversos fatores, tais como: a iniciativa da empresa em acessá-los; o portfólio de recursos da empresa; a participação da empresa na formação do cluster; a base de conhecimento; a capacidade absortiva da empresa e seus relacionamentos interorganizacionais (FENSTERSEIFER e WILK, 2005). A inserção no cluster e o acesso a esses recursos poderão influenciar de modo positivo a geração de vantagens competitivas sustentáveis.

Em outras palavras: o ambiente encontrado e gerado no cluster poderá influenciar seu desempenho e, dessa forma, a competitividade das empresas em diversos níveis. A localização do aglomerado pode ser muito importante para o desempenho das organizações presentes no cluster, porém, nem sempre isso ocorre de maneira homogênea. Isso faz com que seja necessário a compreensão das características específicas das regiões - a Serra Gaúcha, nesse estudo - que poderiam promover ou atrasar o desempenho das empresas (MASKELL, 2001; MOLINA- MORALES, 2001; WILK e FENSTERSEIFER, 2003; CALVET, 2005; MENDEZ e MERCIER, 2006; WILK, 2006).

Entretanto, para que os recursos possam realmente ser fonte de vantagens competitivas sustentáveis, devem atender a quatro requisitos: serem valiosos, serem raros, serem de difícil imitação, e não possuírem substitutos equivalentes estrategicamente. Essa visão vem do modelo proposto por Barney (1996) chamado VRIO - Valor, Raridade, Imitabilidade e Organização.

Assim, a utilização da RBV ao analisar e avaliar os recursos em um cluster, possibilita essa compreensão, diferenciando as regiões, explicando seu desempenho. Os recursos desenvolvidos e compartilhados pelas empresas no ambiente do cluster exercem influência positiva ou negativa no que diz respeito às suas vantagens competitivas (FENSTERSEIFER e WILK, 2005).

Existe uma convergência da tecnologia da informação, dos sistemas de informações gerenciais e da gestão do conhecimento, atuando como ferramentas de gestão para alcançar os objetivos da organização. A integração delas, de maneira conjunta permite que se consigam resultados melhores alcançando a vantagem competitiva(MORAES, et al,2018).

De acordo com Hall e Mitchell (2008), a RBV é muito relevante especialmente no setor vitivinícola, onde fatores como clima, solo, manejo, elaboração do vinho, entre outras particularidades de uma região, são fontes de vantagens competitivas sustentáveis, dependendo da maneira com que são criadas as estratégias.

Dessa forma, a definição de estratégias para uma empresa inicia com a identificação de oportunidades e ameaças em seu ambiente, ou seja, através de uma análise externa. Porém, é necessário determinar se a empresa tem capacidade de levar essas estratégias adiante, o que a leva a fazer uma análise interna ou, nesse caso, uma análise interna do cluster em si, com base em seus recursos e em suas competências. Essa análise mostra as forças e as fraquezas 
do cluster. Na formulação das estratégias, deve-se combinar oportunidades e forças para minimizar o impacto das ameaças e de suas fraquezas (FERRELL et al, 2000; HOOLEY; SAUNDERS; PIERCY, 2001; YANAZE, 2011).

Barney (1991) aponta que a empresa pode obter vantagem competitiva através da análise dos ambientes interno e externo quando decide implementar estratégias para explorar recursos. O autor também argumenta que a empresa poderá ter vantagem competitiva sustentável quando implementa estratégias que explorem suas forças para aproveitar oportunidades ao mesmo tempo em que neutraliza ameaças e evita suas fraquezas. Como o objetivo principal deste estudo é entender como a RBV pode trazer vantagens competitivas para o cluster vitivinícola da Serra Gaúcha, a análise e apresentação do cluster é mostrada no item a seguir.

\section{APRESENTAÇÃO E ANÁLISE DO CLUSTER VITIVINÍCOLA DA SERRA GAÚCHA}

O cluster vitivinícola da Serra Gaúcha está localizado na região nordeste do estado do Rio Grande do Sul, cerca de 120 km da cidade de Porto Alegre, capital do Estado. Trata-se do principal cluster vitivinícola no Brasil, que concentra cerca de $80 \%$ da produção de vinhos do país e uma área de vinhedos de maior que 34.000 ha. A aglomeração concentra cerca de 600 vinícolas e 13.000 produtores de vinhos, quase, em sua totalidade, descendentes de imigrantes italianos (FENSTERSEIFER, 2007; IBRAVIN, 2014).

Entre os municípios produtores de vinhos da Serra Gaúcha estão: Antônio Prado, Bento Gonçalves, Carlos Barbosa, Caxias do Sul, Farroupilha, Flores da Cunha, Garibaldi, São Marcos e Veranópolis. Em termos regionais, o município de Bento Gonçalves é o que responde pela maior parte da produção de vinhos finos e tem maior destaque, já que possui a primeira Denominação de Origem do Brasil.

Como a Serra Gaúcha desempenha um papel importante no setor vitivinícola nacional, o cluster concentra outras organizações atuantes no setor, incluindo instituições públicas, privadas, de formação de recursos humanos, de pesquisa, além de fornecedores de insumos e empresas de turismo (FENSTERSEIFER et al., 2002). Entre as organizações atuantes estão o Ministério da Agricultura, Pecuária e do Abastecimento (MAPA), a Empresa Brasileira de Pesquisa Agropecuária (EMBRAPA), a Secretaria Estadual da Agricultura, as Secretarias Municipais da Agricultura, o Instituto Brasileiro do Vinho (IBRAVIN), a União da Vitivinicultura Brasileira (UVIBRA), a Associação Gaúcha de Vitivinicultores (AGAVI), a Federação Cooperativa do Vinho (FECOVINHO), entre várias outras. Além dessas, existem entidades e associações que atuam na defesa de interesses de grupos específicos, como as Associações de Produtores do Vale dos Vinhedos, de Monte Belo, de Altos Montes - APROVALE, APROBELO e APROMONTES, respectivamente. 
A Serra Gaúcha tem uma viticultura de pequenas propriedades, com pouca mecanização, já que possui uma topografia acidentada, e predomina o uso da mão de obra familiar. Possui, no entanto, alta tecnologia enológica, sobretudo no segmento de vinhos finos e espumantes (SEHNEM et al., 2010). A densidade de plantio está entre 1.600 a 3.300 plantas por hectare, e o sistema de condução em latada ou pérgola (videira conduzida horizontalmente) é o mais encontrado, proporcinando produção de até 30 toneladas por hectare, de acordo com a variedade da uva e as condições climáticas da safra.

A maior parte da uva colhida é destinada à vinificação, sucos e outros derivados. $\mathrm{Na}$ Serra Gaúcha destaca-se a qualidade da produção de espumantes e de vinhos tintos da variedade merlot. Porém, a maior parte da produção da região, em torno de 80\%, é originada de uvas Vitis labrusca, como Isabel, Bordô, Niágara Branca, Concord e Niágara Rosada. Essas variedades são destinadas à produção de sucos e vinhos de mesa, e também para o consumo da uva em si, as uvas de mesa. No que diz respeito às uvas Vitis vinifera, destacam-se as cultivares de uvas brancas como Moscato Branco, Riesling Itálico, Chardonnay e Trebbiano; entre as tintas, as principais são Merlot, Cabernet Sauvignon, Cabernet Franc, Tannat, Ancellota e Pinotage (IBRAVIN, 2010; EMBRAPA).

Em relação aos recursos do cluster da Serra Gaúcha vitivinícola, o terroir pode ser destacado como um recurso de acesso restrito, fonte de vantagem competitiva sustentável, já que é acessível somente para as vinícolas localizadas no cluster (WILK e FENSTERSEIFER, 2003). Quando fala-se em vinhos, o terroir é um dos principais recursos, já que a qualidade do produto está relacionada com o território, o solo, o clima da região, desde o cultivo da uva, a vinificação e as estratégias de comercialização (HALL e MITCHELL, 2008). Esta vantagem competitiva é o que impulsiona o desenvolvimento dos espumantes que hoje são comparados aos melhores espumantes encontrados no mercado mundial e conseguiram despertar o paladar dos consumidores.

No setor vitivinícola, a região de origem pode ser um indicativo de qualidade do produto (qualidade refere-se às características do produto levando em consideração o terroir em que foi produzido) e pode ser um fator importante no processo de tomada de decisão para o consumidor.

Fora do Brasil, é comum que produtos ganhem reputação por causa dos locais onde foram produzidos. Um dos exemplos é do próprio setor vitivinícola, que possui toda uma regulamentação em que os produtores recebem um selo de Indicação de Procedência, de Denominação de Origem Controlada, entre outros. O caso mais conhecido é o Champagne, que possui denominação de origem controlada, ou seja, fora da região de Champagne na França, nenhum produto pode ser chamado de Champagne, já que o original tem características e qualidades distintas do espumante produzido em qualquer outro lugar do mundo.

Na Serra Gaúcha, existe a primeira Denominação de Origem do Brasil, o Vale dos 
Vinhedos. Existem outras regiões do cluster que também estão em processo de registro, e algumas que já possuem o selo de Indicação de Procedência, como é o caso de Monte Belo (APROBELO), e Altos Montes (APROMONTES) (IBRAVIN, 2010).

Toda a coordenação estratégica, não só para este cluster, mas também para o Brasil é responsabilidade do IBRAVIN, localizado no cluster da Serra Gaúcha, e articula as principais ações coletivas do setor. Uma das principais ações coordenadas pelo Instituto foi o Programa 2025 (FENSTERSEIFER, 2007). Criado no final de 2005, o programa projeta um horizonte de 20 anos, e foi formulado através de um processo participativo envolvendo representantes de diversas áreas do cluster. É importante dar destaque para o caráter participativo do planejamento, já que é uma característica que o distingue relativamente de planejamentos similares feitos em outros países (FENSTERSEIFER, 2007). Sua superioridade está no fato de que o setor redescobriu sua capacidade de coletividade e cooperação, formulando e colocando em prática ações estratégicas que estão levando o cluster melhorar as possibilidades de um desenvolvimento sustentável.

\section{METODOLOGIA}

Este artigo consiste em uma pesquisa básica de revisão de literatura. De acordo com Casarin e Casarin (2011), a pesquisa básica consiste em obter e aprimorar o conhecimento científico sem a preocupação de uma aplicação prática imediata.

Com base nos objetivos propostos por este trabalho, a pesquisa pode ser classificada como exploratória. Gil (1999) afirma que estudos exploratórios têm como principal objetivo dar uma visão geral sobre um fato específico, quando se está buscando conhecimento de um tema pouco explorado. Malhotra (2001, p. 105) afirma que "o principal objetivo da pesquisa exploratória é prover a compreensão do problema enfrentado pelo pesquisador". Gil (1999), também afirma que as pesquisas exploratórias são realizadas por meio de estudos de caso, entrevistas com pessoas especializadas ou por revisão de literatura

Neste estudo foram utilizadas duas técnicas de coleta de dados: pesquisa bibliográfica e pesquisa documental. Para Stumpf (apud Duarte \& Barros, 2005, p. 51). A pesquisa bibliográfica é o planejamento global inicial de qualquer trabalho de pesquisa, que vai desde a identificação, localização e obtenção da bibliografia pertinente sobre o assunto, até a apresentação de um texto sistematizado, onde é apresentada toda a literatura que o aluno examinou, de forma a evidenciar o entendimento do pensamento dos autores, acrescido de suas próprias ideias e opiniões.

Já a pesquisa documental em muito se assemelha à bibliográfica e, de acordo com Gil (1999), utiliza materiais que ainda não tiveram tratamento analítico tais como reportagens de jornais, filmes, gravações, relatórios, etc, ou seja, em documentos e fontes primárias. 
Esta parte foi realizada junto ao IBRAVIN, com conversas, visitas e até mesmo consultando o site da instituição.

De acordo com Gil (1999), as pesquisas desse tipo não possuem regras rígidas para sua realização. Porém, o autor cita algumas tarefas importantes no processo:

a) Exploração da bibliografia, artigos, documentos, etc, onde são encontradas

informações pertinentes ao problema de pesquisa bem como novas fontes de referências;

b) Leitura seletiva do material encontrado, retendo os fragmentos essenciais para o desenvolvimento do artigo;

c) Fichamento e ordenação do material, resumindo as partes mais importantes do material consultado;

d) Conclusões obtidas a partir da análise do material fichado e ordenado.

Com este trabalho pretende-se estender o conhecimento sobre os temas abordados: clusters e RBV, analisando a utilização dos conceitos no cluster vitivinícola da Serra Gaúcha. Assim, será possível entender quais são as melhores formas para a aplicação da RBV, possibilitando que estudos posteriores as coloquem em prática.

\section{DISCUSSÃO E ANÁLISE}

Em se tratando de fornecimento de insumos, as vinícolas maiores tem mais poder de negociação em relação aos preços, e conseguem adquirir diretamente do fabricante. As empresas menores, com pequena demanda, adquirem os insumos no comércio da região. $\mathrm{E}$ com isso, estão formando redes para compra compartilhada dos insumos, aumentando a quantidade comprada e, consequentemente, o poder de barganha (ZEN, 2010).

No trabalho de Zen (2010), observou-se que uma das principais dificuldades do cluster é a logística de distribuição. A localização geográfica do cluster no sul do país dificulta a distribuição para o mercado interno, principalmente para as pequenas vinícolas cujos setores de logística são pouco estruturadas. Uma outra dificuldade é a questão da tributação, que muda de estado para estado e dificulta o processo de comercialização e precificação dos produtos.

Mesmo com o planejamento Visão 2025, o cluster da Serra Gaúcha ainda é carente de uma instituição responsável especificamente pelo cluster, já que o IBRAVIN congrega o setor vitivinícola do país inteiro. Não existe hoje uma instituição que se dedique exclusivamente na análise dos recursos de forma que estes sejam base de um planejamento estratégico de promoção do cluster.

Este fato torna-se impeditivo, já que existem dois modelos distintos no setor 
vitivinícola. Como observa Ditter (2005), o primeiro é o modelo tradicional do Velho Mundo, baseado no certificado de denominação de origem, que tem por objetivo tornar um produto típico de alto valor agregado, produzido em pequenas quantidades, por meio do terroir e de regulamentações e especificações restritivas à determinadas práticas de elaboração de vinhos. Ditter (2005) aponta que o segundo modelo é baseado em produtos industrializados, relativamente padronizados, produzidos em massa, facilmente identificados por causa de marcas privadas e com muito marketing, modelo característico dos países produtores do Novo Mundo, incluindo o Brasil.

Mesmo que o cluster da Serra Gaúcha tenha diversos recursos que o tornariam estrategicamente sustentáveis, a falta de planejamento de marketing específico do cluster é um ponto muito negativo. Atualmente os órgãos responsáveis pelo setor fizeram um planejamento baseado nos modelos do Velho Mundo que, como observado anteriormente, possui características bem distintas das que encontramos aqui.

No âmbito do marketing, entre os principais desafios do cluster estão: dificuldades de distribuição, já que está localizado no sul do país; a manutenção do equilíbrio entre produção e consumo de vinho; vinhos importados do Chile e Argentina com preços extremamente competitivos; e o crescimento de novos produtores na Ásia.

Além disso, o Brasil como um todo ainda não é reconhecido como país produtor de vinho, nem nacionalmente, nem internacionalmente. Isso só demonstra a deficiência do planejamento de marketing tanto para o setor quanto para o cluster em si, já que é o responsável por quase toda a produção de vinho do país. É claro que foram criados programas como o Wines of Brazil, um programa que tem funcionado bem, mas que ainda tem muito a melhorar.

Estes desafios, entre diversos outros, indicam que a indústria vitivinícola caracterizase por um mercado complexo, e tem concorrência acirrada com outros países, principalmente após a redução de barreiras comerciais. Nesse sentido, avaliar os recursos do Cluster da Serra Gaúcha, modificar culturas e crenças organizacionais, para adotar a Visão Baseada em Recursos para criar estratégias adequadas à cultura local, aos desejos dos consumidores, para atrair novos clientes e até mesmo para a internacionalização, é essencial. A RBV então, pode auxiliar o cluster a se organizar para aprimorar forças, diminuir fraquezas, aproveitar oportunidades e amenizar ameaças, criando vantagens competitivas sustentáveis em relação aos outros produtores de vinhos no país e formando uma reputação nacional para depois ter reputação internacional.

O enoturismo e a gastronomia da Serra Gaúcha são excelentes exemplos de recursos que poderiam ser melhor aproveitados, afinal, são recursos que nenhuma outra região pode imitar. O desenvolvimento do enoturismo na região estimula a relação direta do consumidor com a vinícola, o que contribui para a educação dos consumidores, fidelização da marca, 
formação de um banco de dados sobre os clientes e obtenção da perspectiva do consumidor em relação ao produto.

\section{CONSIDERAÇÕES FINAIS}

O presente estudo buscou avaliar de que forma a Visão Baseada em Recursos pode ser aplicada no cluster da Serra Gaúcha de forma a criar vantagens competitivas. Para isso, foi feita uma revisão da literatura sobre os assuntos, incluindo um artigo que criou um instrumento de análise interna do cluster, que poderá ser utilizada em estudos posteriores e para o planejamento estratégico do cluster em si.

Conforme apresentado, o cluster da Serra Gaúcha é o principal produtor de vinhos do país, e tem destaque em alguns produtos como espumantes e vinhos da variedade merlot. Temos aqui uma vantagem competitiva muito evidente e que dificilmente conseguirá ser copiada. Trata-se do terroir . O terroir é um recurso de acesso restrito e uma ótima fonte de vantagem competitiva às empresas vinícolas intaladas dentro do cluster. A qualidade do produto fica relacionada ao território, ao clima, ao solo da região e a todo processo que comumente as pessoas de descendência italiana utilizam para produzir seus produtos.

E justamente o terroir é a vantagem competitiva atribuída aos espumantes produzidos no cluster. Estes provaram serem de excelente qualidade em função dos variados prêmios conquistados nos últimos anos em concursos internacionais. O local é o que os diferencia de outros espumantes produzidos em autras áreas.

Contudo, não existe uma instituição responsável por planejar estrategicamente as ações do cluster, atividade que hoje é feita pelo IBRAVIN, que regula e orienta o setor do país inteiro. Por mais que a sede do IBRAVIN esteja localizada dentro do cluster, a atenção necessária para um planejamento estratégico eficiente e eficaz não pode ser dada, devido a tantas outras obrigações e atividades do Instituto.

O vinho é um dos poucos produtos industrializados cujos atributos conduzem a uma cooperação e coletividade em nível regional, uma vez que a região produtora pode diferenciar e agregar valor aos seus produtos, principalmente através da RBV. Dessa forma, a criação de uma entidade responsável pelo cluster é um elemento central de extrema importância, já que o cluster proporciona facilidade e compartilhamento de benefícios, onde os participantes do cluster podem incluir ações de promoção e divulgação, troca de conhecimentos sobre o mercado, aumento da capacidade de pesquisa, treinamento conjunto de funcionários além do compartilhamento da infraestrutura de marketing. Isto irá fortalecer a imagem do cluster, aumentando sua reputação e trazendo vantagens competitivas sustentáveis.

O cluster da Serra Gaúcha tem potencial, e se destaca inclusive internacionalmente, mas precisa analisar melhor seus recursos e a maneira como eles podem ser estratégicos, 
principalmente com espumantes e vinhos tintos da variedade merlot, que já possuem reputação firmada.

\section{REFERÊNCIAS}

BARNEY, J. B. Strategic factor markets: expectations, luck and business strategy. Management Science, v. 32, n. 10, p.1231-1241, 1986.

BARNEY, J.B. Firm Resources and Sustained Competitive Advantage. Journal of Management, v.17, p.99-120, 1991.

BARNEY, J.B. Gaining and Sustaining Competitive Advantage. Reading - MA: Addison-Wesley Publishing Company, 1996.

BELSO-MARTINEZ, J.A. Why are some Spanish manufacturing firms internationalizing rapidly? The role of business and institutional international networks. Entrepreneurship \& Regional Development, v. 18, 207-226, Maio, 2006.

BECATTINI, G. Italian Industrial District: Problems and Perspectives. International Studies of Management \& Organization, v. 21, n. 1, p. 83 -90, Spring, 1991.

CALVET, J. Les Clusters Vitivinicoles Français a AOC: Une analyse en termes de biens clubs. Working Paper, 2005.

CASARIN, Helen; CASARIN, Samuel. Pesquisa científica: da teoria à prática. Curitiba: Ibpex, 2011.

CASSIOLATO, J. E.; LASTRES, H.M.M. O foco em arranjos produtivos e inovativos locais de micro e pequenas empresas. In: LASTRES, H.M.M.; CASSIOLATO, J.E.; MACIEL, M.L. (Orgs.) Pequena Empresa: Cooperação e Desenvolvimento Local. Rio de Janeiro: Relume Dumará, 2003.

DAS, T. K.; TENG, B. S. A Resource-based theory of strategic alliances. Journal of Management, v. 26, n. 1, p. 31-61, 2000.

DIERICKX, I.; COOL, K.; BARNEY, J.B. Asset stock accumulation and the sustainability of competitive advantage. Management Science, v. 35, n. 12, p.1504- 1511, 1989.

DITTER, J.-G. Reforming the French Wine Industry: Could Clusters Work? Cahiers du CEREN, v.13, p. 39-54, 2005.

DYER, J.H.; SINGH, H. The Relational View: Cooperative Strategy and Sources of Interorganizational Competitive Advantage. Academy of Management Review, v. 23, n. 4, p. $660-679,1998$.

FENSTERSEIFER, J.E. The emerging Brazilian wine industry: challenges and prospects for the Serra Gaúcha wine cluster. International Journal of Wine Business Research, v. 19, n.3, 2007. 
FENSTERSEIFER, J.E.; WILK, E.O. Visão da Firma Baseada em Recursos, Clusters e Performance: Um Estudo no Setor Vitivinícola do RS. In: XXIX Encontro da Associocao Nacional dos Programas de Pos-Graduacao em Administracao. Brasília, 2005.

FERRELL, O. C.; HARTLINE, Michael D.; LUCAS Jr, George H.; LUCK, David. Marketing Strategy. São Paulo: Atlas, 2000.

GIL, Antonio Carlos. Métodos e técnicas de pesquisa social. 5 ed. São Paulo: Atlas, 1999.

GRANT, R.M. The resource-based theory of competitive advantage. California Management Review, v.33, n.3, p. 114-135, 1991.

GULATI, R. Network Location and Learning: The Influence of Network Resources and Firm Capabilities on Alliance Formation. Strategic Management Journal, v.20, p.397-420, 1999.

HALL, M. C.; MITCHELL, R. Wine Marketing: A Practical Guide. USA, Barlington:

Elsevier, 2008.

HOOLEY, Graham J.; SAUNDERS, John A.; PIERCY, Nigel F.. Marketing Strategy

and Competitive Positioning. 2ed. São Paulo: Prentice Hall, 2001.

ITAMI, H. Invisible Assets. In: ITAMI, H. (Eds). Mobilizing Invisible Assets. Harvard University Press, Cambridge, 1987.

IBRAVIN. Disponível em http://www.ibravin.org.br.

LAVIE, D. The Competitive Advantage Of Interconnected Firms: An Extension Of The Resource-Based View. Academy of Management Review, v. 31, n. 3, pp. 638-658, 2006.

MAFEZOLLI,E. Programa de Treinamento e Desenvolvimento Através da Leitura para os Colaboradores Técnico Administrativos do Centro Universitário de Brusque. Revista Visão: Gestão Organizacional. Volume 06, no 01, 2017.

MALHOTRA, Naresh K. Pesquisa de marketing: uma orientação aplicada. Porto Alegre: Bookman, 2001.

MARSHALL, A. (1890) Princípios de Economia. São Paulo: Nova Cultural, 1983.

MASKELL, P., Towards a Knowledge based Theory of the Geographical Cluster. Industrial and Corporate Change, v.10, n.4, p.921-943, 2001.

MENDEZ, A.; MERCIER, D. Compétences-clés de territoires: Le role dês relations interorganisationnelles. Revue française de gestion, n. 164, p. 253-275, 2006.

MESQUITA, L.F.; ANAND.J.; BRUSH, T. Comparing The Resource-Based And Relational Views: Knowledge Transfer and Spillover in Vertical Alliances. Strategic Management Journal, v. 29, pp. 913-941, 2008. 
MOLINA-MORALES, F.X. European industrial districts: Influence of geographic concentration on performance of the firm, Journal of International Management, v. 7, pp. 277-294, 2001.

MORAES,J,P; SAGAZ,S,M; SANTOS,G,L; LUCIETTO,D,A.Tecnologia da Informação, Sistemas de Informações Gerenciais e Gestão do Conhecimento com Vistas à Criação de Vantagens Competitivas: Revisão de Literatura. Revista Visão: Gestão Organizacional, Vol 07, no001, 2018. NADVI, K; SCHMITZ, H. Industrial Clusters in Developing Countries. World Development, v. 27, n. 9, pp.1503-1514, 1999.

NANDA, A. Resources, Capabilities and Competencies, In: MOINGEON, B.; EDMONSON, A. (Eds.), Organizational Learning and Competitive Advantage. p. 93-120. Sage, 1996.

PETERAF, M. A. The cornerstones of competitive advantage: a resource based-view. Strategic Management Journal, v. 14, p. 179-191, 1993.

PORTER, M.E. Clusters and the new economics of competition. Harvard Business Review, v. 76, n. 6, nov./dec., p. 77-90, 1998.

PRAHALAD C. K.; HAMEL, G. The core competence of the corporation. Harvard Business Review, may-june, p.79-91, 1990.

SCHMITZ, H. Global Competition and Local Cooperation: Success and Failure in the Sinos Valley, Brazil. World Development, v. 27, n. 9, pp. 1627-1650, 1999.

SEHNEM, Alyne et al. Estratégia e competitividade sistêmica: estudo de caso do setor vitivinícola da serra gaúcha. RACE - Revista de Administração, Contabilidade e Economia, [S.I.], v. 9, n. 1-2, p. 67-90, dez. 2010. ISSN 2179-4936. Disponível em:

<http://editora.unoesc.edu.br/index.php/race/article/view/551>. Acesso em: Jan. 2014.

SÖLVELL, Ö. Clusters - Balancing Evolutionary and Constructive Forces, 2.ed., Ödeshög: Danagards Grafiska, 2009.

TEECE, D.J.; PISANO, G.; SHUEN, A. Dynamic capabilities and strategic management. Strategic Management Journal, v. 18, n. 7, p. 509-533, 1997.

WERNERFELT, B. A Resource-Based View of The Firm. Strategic Management Journal, v. 5, n. 2, p.171-180, 1984.

WILK, E. A Relacao entre Estratégia, Recursos e Performance: Uma investigacao em Empresas de Vinhos Finos do Cluster da Serra Gaúcha. 227 p. Tese (Doutorado em Agronegócios).

Centro de Estudos e Pesquisa em Agronegócios, Universidade Federal do Rio Grande do Sul, Porto Alegre, 2006

WILK, E.; FENSTERSEIFER, J.E. Use the Resourced-based View in Industrial Cluster Strategic Analysis. International Journal of Operations \& Production Management. V. 23; n.9; p. 995 1009, 2003. 
YANAZE, Mitsuru Higuchi. Gestão de Marketing e Comunicação: avanços e aplicações. 2ed. São Paulo: Saraiva, 2011.

ZEN, Aurora C. A Influência dos recursos na internacionalização de empresas inseridas em clusters: uma pesquisa no setor vitivinícola no Brasil e na França. Tese Doutorado, Universidade Federal do Rio Grande do Sul, Programa de Pós- Graduação em Administração. Porto Alegre, 2010, 270f. 